\title{
AC 2009-969: THE DEVELOPMENT OF A FORMAL RESEARCH STUDY ON CORRELATING STUDENT ATTENDANCE WITH STUDENT SUCCESS
}

\section{Donald Richter, Eastern Washington University}

DONALD C. RICHTER obtained his B. Sc. in Aeronautical and Astronautical Engineering from The Ohio State University, M.S. and Ph.D. in Engineering from the University of Arkansas. He holds a Professional Engineer license and worked as an Engineer and Engineering Manger in industry for 20 years before teaching. His interests include project management, robotics /automation , parametric modeling and rapid prototyping.

\section{William Loendorf, Eastern Washington University}

William R. Loendorf is currently an Associate Professor of Engineering \& Design at Eastern Washington University. He obtained his B.Sc. in Engineering Science at the University of Wisconsin - Parkside, M.S. in Electrical Engineering at Colorado State University, M.B.A. at the Lake Forest Graduate School of Management, and Ph.D. in Engineering Management at Walden University. He holds a Professional Engineer license and has 30 years of industrial experience as an Engineer or Engineering Manager at General Motors, Cadnetix, and Motorola. His interests include engineering management, real-time embedded systems, and digital signal processing.

\section{Jason Durfee, Eastern Washington University}

Jason Durfee received his BS and MS degrees in Mechanical Engineering from Brigham Young University. He holds a Professional Engineer certification. Prior to teaching at Eastern Washington University he was a military pilot, an engineering instructor at West Point and an airline pilot. His interests include aerospace, aviation, professional ethics and piano technology

\section{Terence Geyer, Eastern Washington University}

Terence L. D. Geyer is currently a Lecturer in the Department of Engineering \& Design at Eastern Washington University. He obtained his B.S. in Manufacturing Technology and M.Ed. in Adult Education in a specially combined program of Technology and Education at Eastern Washington University. His interests include collecting and re-manufacturing older technologies. 


\title{
The Development of a Formal Research Study on Correlating Student Attendance to Student Success
}

\begin{abstract}
It is generally accepted that today's engineering technology students are very different from the students of 20 years ago. They are of the "digital age" and are assumed to have different learning styles than the traditional students of generations before, although one might suggest that the teaching methods of the past did not work well even for earlier generations. One of the long established tenets of teaching is that attendance in class leads to student success. A research study is being initiated to examine if this correlation currently exists and if so to what extent. This paper describes the formulation, methodology and design of this study to formally test the relationship of attendance with student success. This is the start of a formal five year research study to determine the impact of attendance in class, whether attendance has a correlation with student success, and does this correlation change during the progression of a student throughout their undergraduate experience. The study will involve students from Mechanical Engineering Technology, Computer Engineering Technology, Manufacturing Technology, Construction Management, and a service course to the general student body. Data will be derived from four different instructors who will teach approximately 20 classes per year ranging from freshman to senior students. One of the objectives of the study is to track an individual student over their entire undergraduate education. The study will also determine if this correlation changes as the student progresses.
\end{abstract}

\section{Introduction}

Today's students are fundamentally different than those from the past. They have more technology at their disposal to either support their studies or distract them from studying. These "digital age" students also exhibit different learning styles that can be traced back to their technology and its use. Few visit the library to do research, but they all search for information online. They spend more time staring at screens whether it is a computer, cell phone, PDA, IPod, television, or movie than they do reading books. Technology has changed their expectations along with their classroom experiences. Perhaps even their need to attend class.

It is generally accepted that attending class has a positive correlation with student success leading to a better understanding of the course material. Studies by Cohn and Johnson ${ }^{3}$ (2006); Davidovitch and Soen ${ }^{4}$ (2006); Moore ${ }^{7}$ (2003); White, Thomas, Johnson, and Hyde ${ }^{12}$ (2008); and many others have investigated the effects of class attendance and discovered supporting results. Class attendance was one of the factors that students control leading to academic success as examined by Dollinger, Matyja, and Huber ${ }^{5}$ (2008); Yudko, Hirokawa, and Chi ${ }^{13}$ (2008); and Webb, Christian, and Armitage ${ }^{11}$ (2007). Incentives, penalties, and motivators for attending class were considered by Brooks, Burton, Cole, Miles, Torgerson, and Torgerson ${ }^{2}$ (2008); Gump ${ }^{6}$ (2005); and Moore $^{8}$ (2005). 
Class attendance is only one of the many factors that determine a student's success in college. However, it is the easiest to measure and determine. It is also one aspect largely under student control. Some students have health, work, or family reasons for missing class while most simply decide whether or not to attend. In the later case, it is their choice as they weigh the cost versus benefit of attendance. They need to determine if is it really worth their time, effort, and bother to attend or by skipping will little knowledge be lost. Only the student can make this determination.

With this in mind, a research project was initiated to determine the actual effects of class attendance on student success. While similar studies conducted in the past concentrated on nonengineering courses ${ }^{1,3,9,10,12,13}$, this project focuses entirely on courses taken by engineering technology students. The objective is to determine if class attendance really leads to better grades. This study will determine if a correlation exists between class attendance and student success, and if so, to what extent.

\section{Project Design}

The project involves several classes at various student ranks all the way from freshman to junior level. The student's attendance for each class is being recorded each day. The success for each student can thus be tracked and measured against his/her attendance in the class. Data will be available for the class as a whole and on the individual level.

The courses have been carefully selected to give a representation of the various class instructional modes seen by Engineering Technology students (lecture-nonmathematical, lecturemathematical, lecture/lab, lecture/demonstration). The project is also being conducted using four separate instructors who have agreed to participate in the project research. The use of more than a single instructor is an attempt to enable a more representative sample of the type of instruction that a student experiences during his/her academic career at the university. This use of multiple instructors will also help minimize the effect of a given instructors influence on student success.

The research study will be conducted over a five-year period. The benefit of using multiple years allows the project to track an individual student through multiple courses and also allows for a larger sampling verses just a one year snapshot. The projected number of students involved in the classes to be used as part of the study is approximately 650 students per year.

Following is a description of each class and the mode and method of instruction. Also the professor that is teaching each class is identified with the description as well as his attendance policy used in the course. Since attendance polices also vary, the effect of this on student success is another aspect to be reviewed by the project.

TECH208 Survey of Electricity, a lecture/lab course is offered by professor 2. This course is a traditional first course in electronics and electrical circuit analysis. The attendance is taken with a daily sign-in sheet. The course has a two-hour weekly laboratory. The attendance policy for this course includes a penalty for missing class. The policy as stated in the course syllabus is: "Missing class will have a very negative impact on your final grade for the course. Three to five unexcused absences will reduce your course point total by $10 \%$ and six or more unexcused absences will reduce your course point total by $25 \%$." From this, you will notice that a 
significant harmful outcome on the student's final course grade results from repeatedly missing class.

TECH 393 Technology in World Civilization, will be taught by two different professors, professor 2 and professor 4. This is a traditional lecture-nonmathematical mode of instruction course. Professor 4 has a policy that attendance is taken through the use of a daily roll call. This is necessitated because the class is taught in one location, and broadcast by simultaneous interactive television to three additional remote locations. Each class session is worth 5 points for a course total of 100 points. This total makes up 11 percent of each students total grade. For the analysis of this class, excused absences will not be counted. This class is structured as four hours of lecture per week. Professor 2 teaches the same class with attendance is taken with a daily sign-in sheet. The attendance policy includes a penalty for missing class. The policy as stated in the course syllabus is: "Missing class will have a very negative impact on your final grade for the course. Three to five unexcused absences will reduce your course point total by $10 \%$ and six or more unexcused absences will reduce your course point total by $25 \%$." From this, you will notice that a significant harmful outcome on the student's final course grade results from repeatedly missing class.

TECH 320 Non-Metallics, uses a lecture/laboratory mode of instruction. Professor 4 teaches this class and attendance is taken through the use of a daily sign-in sheet. Each class session is worth 2.5 points and the total points awarded for attendance is 50 points, which makes up 10 percent of each students total grade. For the analysis of this class, excused absences will not be counted. This class is structured as two hours of lecture and seven hours of lab per week.

ENGR 110 Engineering Graphics is taught by professor 3. This course consists of both lecture and laboratory/demonstration periods. Attendance is not required for either the lecture or the laboratory. It is clearly explained to the students at the beginning of the course that attendance is not required however; the instructor is not willing to assist students in making up missed material for unexcused absences. The laboratory/demonstration periods are interspersed with the lecture periods. This gives the students opportunity for individualized assistance from the instructor with assigned work. A tutorial-style text is used allowing students to work and some students with a CAD background may need minimal lecture attendance to assimilate the course material. A huge percentage, $80 \%$ of the course grade comes from technical drawings and the remainder from two exams. Students get the greatest assistance with the assigned drawings by attending all lectures and taking advantage of the laboratory/demonstration periods. Attendance is taken daily by distributing a roll to the students requiring their signature to be marked as present.

TECH 341 Strength of Materials, is taught by professor 3. The course is a lecture-mathematical style course and attendance is not required. It is clearly explained to the students at the beginning of the course that attendance is not required. However, the instructor is not willing to assist students in making up missed material for unexcused absences. Attendance is taken daily by distributing a roll to the students requiring their signature to be marked as present.

TECH 340 Statics, is taught by professor 1. The course uses a lecture-mathematical mode of course instruction. The attendance is taken with a daily sign-in sheet. Attendance is not 
mandatory however, the professor allows students who miss three or less lectures to drop the lowest of four exams given during the course.

TECH 385 Robotics and Automated Systems is taught by professor 1 . The course uses a lecturelaboratory mode of course instruction. The attendance is taken with a daily sign-in sheet. Attendance is not mandatory. However, the professor allows students who miss three or less lectures to drop the lowest of four exams given during the course.

\section{Project Outcomes}

The main purpose of this study is to test the existence of a relationship between attendance and student success in engineering technology courses. Three other aspects will also be investigated. First, do incentives resulting from attending classes foster better attendance? Second, do penalties inflicted on final grades for missing classes improve attendance? Third, what affect does not grading attendance have on class attendance?

With these objectives in mind, four important questions will be considered for improving student success. First, do students have a better likelihood of success in the courses they take by attending class? Second, does attendance (one of the easiest variables for academic success that students control) affect student success? Third, should professors encourage attendance and stress its importance? Fourth, do attendance incentives (positive, negative, or none) have an influence on student success? The answers to these questions will lead to the outcomes from this research study.

There is no magic secret for academic success. It is based on a complex combination of ability, drive, motivation, and hard work. However, attending class has been shown in past ${ }^{1,3,4,7,9}$ studies to be a positive influence on general student success. This study proposes to determine if this is still valid for students taking engineering technology courses.

\section{Project Update}

The project has just completed its first Quarter and the project researchers are evaluating the data collected. There is still much to be learned throughout the duration of the project. The relationship between attendance and student success is much more complicated than one would first conclude and the relationship of how attendance may be impacted by instructor policies can complicate the study.

Anecdotal evidence seems to suggest (in the first quarter of the study) that in the classes where attendance is not being used as part of the grade, attendance declined. This decline occurred after the students inquired why attendance was being taken. Even though they were told at the beginning of quarter that the attendance was not being graded, the instructor once again restated this reality. After that second explanation, the evidence seems to indicate that students are even more likely to miss class because they have a firm confirmation that attendance is not being graded. 
There were a few additional observations from the first quarter's data. Courses that utilized some form of incentive, whether positive or negative showed a higher percentage of attendance. The professors that promoted class attendance also had comparable higher percentages. Classes for which attendance was not required showed lower percentages, as expected.

The second Quarter is underway and data collection continues. Succeeding Quarters will also have attendance taken with the data processed and analyzed. As more data is collected and analyzed, it will lead to conclusions relating to the stated outcomes for this study. The researchers will be also looking for trends linking attendance to classroom success or signs that indicate otherwise.

\section{Conclusions and Future Plans}

This study proposes to validate the following generally accepted conclusions. Even though class attendance does not guarantee success in any course, it is a major indicator of the student's interest, attitude, actions, and motivation. Student's that attend classes are also more likely to read and study the material outside of the classroom, complete their assignments on time, and learn more from the course. However, some students separate learning from class attendance and believe they can gain the knowledge on their own. This may be true for some fields of study, but for rigorous engineering technology courses, it is more difficult.

This study examines student attendance to determine how it relates to student success. Many aspects are under consideration including incentives, penalties, and no emphasis on attendance. The findings from this study will indicate the implications resulting from these attendance policies and procedures.

This is the beginning of a multi-year study into student attendance and academic success. The data collection process has begun and will continue for many Quarters to come. The results should be useable and applicable to other institutions that offer engineering technology and engineering programs. Project updates will be available in future papers as the data is collected and analyzed.

\section{Bibliography}

1. Boss, S.K. (2008). Impact of Student Attendance on Student Learning in An Introductory Geology Course. Proceedings of the Joint Meeting of the Geological Society of America, Soil Science Society of America, American Society of Agronomy, Crop Science Society of America, Gulf Coast Association of Geological Societies with the Gulf Coast of SEPM, 40(6):307.

2. Brooks G, Burton M, Cole P, Miles J, Torgerson C, \& Torgerson D. Randomised Controlled Trial of Incentives to Improve Attendance at Adult Literacy Classes. Oxford Review of Education. October 2008;34(5):493-504.

3. Cohn E, \& Johnson E. Class Attendance and Performance in Principles of Economics. Education Economics. June 2006;14(2):211-233.

4. Davidovitch N, \& Soen D. Class Attendance and Students' Evaluation of their College Instructors. College Student Journal. September 2006;40(3):691-703.

5. Dollinger S, Matyja A, \& Huber J. Which factors best account for academic success: Those which college students can control or those they cannot?. Journal of Research in Personality. August 2008;42(4):872-885.

6. Gump S. The Cost of Cutting Class. College Teaching. Winter2005 2005;53(1):21-26. 
7. Moore R. Attendance and Performance. Journal of College Science Teaching. March 2003;32(6):367.

8. Moore R. Attendance: Are Penalties More Effective Than Rewards?. Journal of Developmental Education. Winter2005 2005;29(2):26-32.

9. Tiruneh, G. Does Attendance Enhance Political Science Grades? Journal of Political Science Education. 2007;3:265-276.

10. Urban-Lurain, M. \& Weinshank, D.J. (2000). Attendance and Outcomes in a Large, Collaborative Learning, Performance Assessment Course. Proceedings of the Annual Meeting of the American Educational Research Association (AERA).

11. Webb T, Christian J, \& Armitage C. Helping students turn up for class: Does personality moderate the effectiveness of an implementation intention intervention?. Learning \& Individual Differences. September 2007;17(4):316-327.

12. White K, Thomas I, Johnston K, \& Hyde M. Predicting Attendance at Peer-Assisted Study Sessions for Statistics: Role Identity and the Theory of Planned Behavior. Journal of Social Psychology. August 2008;148(4):473-492.

13. Yudko E, Hirokawa R, \& Chi R. Attitudes, beliefs, and attendance in a hybrid course. Computers \& Education. May 2008;50(4):1217-1227. 